\title{
EDITORIAL \\ Shifting paradigms: how pediatric neurosurgeons view prenatal closure for myelomeningocele
}

\author{
Erin N. Kiehna, MD \\ Department of Neurosurgery, Novant Health Neurosciences and Psychiatry Institute, Charlotte, North Carolina
}

$\mathrm{T}$ HE first prenatal myelomeningocele (MMC) repair by hysterotomy took place just 22 years ago in 1997. ${ }^{1}$ Inspired by the initial outcomes, collaborators at Vanderbilt, Children's Hospital of Philadelphia, and the University of California, San Francisco performed the procedure on more than 200 carefully selected fetuses over the next 5 years. The early outcomes showed improvement in hindbrain herniation and reduction in ventriculoperitoneal shunting in the surviving infants (compared to historical controls), but at the cost of increased maternal risk, including preterm labor and uterine dehiscence., ${ }^{4,5}$ The Management of Myelomeningocele Study (MOMS) was launched in 2003 to compare the safety and efficacy of prenatal repair of $\mathrm{MMC}$ with that of standard postnatal repair. The trial closed early in December 2010, following randomization of 183 eligible women, because the data proved the efficacy of prenatal surgery. ${ }^{2}$

Fast forward to 2019, and there are now more than 20 centers in the US and another 30-plus centers worldwide performing fetal MMC closures via fetoscopic or mini-hysterostomy techniques. With the press lauding the promising results as "a miracle" and perhaps a new standard of care, few draw attention to the maternal and fetal risks. ${ }^{4}$ It is therefore timely and appropriate to query pediatric neurosurgeons, both in the US and globally, regarding their interpretation of the MOMS results and the evolution of their practice patterns in the post-MOMS era.

Riley et al. surveyed the membership of the American Society of Pediatric Neurosurgeons regarding views pertaining to intrauterine closure of MMC. Their survey attained a $65 \%$ response rate from the 154 members and found that pediatric neurosurgeons generally viewed intrauterine closure of MMC favorably (71\%). ${ }^{3}$ Of those surveyed, the majority (74\%) were older than 50 years of age with the wisdom of 20-plus years of experience. Although some respondents may be part of the centers across the US taking part in fetal closures, most trained and began practice in an era in which fetal surgery was not a viable option. The respondents older than 50 years of age were less likely to recommend fetal closure. Perhaps there is greater recognition in the more senior colleagues that MOMS was conducted under strict criteria, with the maternal and fetal risks being downplayed or not presented. Of the total respondents, $51 \%$ were likely to recommend prenatal surgery in light of the MOMS results. Appreciation of those risks may be the rationale for why pediatric neurosurgeons were actually less likely to recommend fetal closure than their non-neurosurgeon colleagues $(69 \%)$.

The authors discovered that there was a lack of consensus on the management of hydrocephalus in infants with an MMC. Unfortunately, these investigators were unable to elucidate the basis for the high variability. In order to provide accurate rates of CSF diversion in the prenatal and postnatal closure cohorts, we should use the same diagnostic and treatment criteria.

As we look to the future, it is critical that we provide external validation for MOMS. Practice guidelines should be established and potential patients should be prospectively enrolled in multicenter research groups. There should be a transparent discussion of the inclusion and exclusion criteria, with ongoing analysis of results as these criteria are broadened or narrowed. We should aim to determine the percentage of fetuses eligible for prenatal closure and aspire to provide these families with comprehensive prenatal counseling to help them make an informed decision. As MOMS taught us, we can dramatically improve the lives of selected children with spina bifida. We have an obligation to both the mothers and their children to proceed into the prenatal surgery era with the proviso "first do no harm."

https://thejns.org/doi/abs/10.3171/2019.8.FOCUS19641 


\section{References}

1. Adzick NS, Sutton LN, Crombleholme TM, Flake AW: Successful fetal surgery for spina bifida. Lancet 352:1675-1676, 1998

2. Adzick NS, Thom EA, Spong CY, Brock JW III, Burrows PK, Johnson MP, et al: A randomized trial of prenatal versus postnatal repair of myelomeningocele. N Engl J Med 364:993-1004, 2001

3. Riley JS, Antiel RM, Flake AW, Johnson MP, Rintoul NE, Lantos JD, et al: Pediatric neurosurgeons' views regarding prenatal surgery for myelomeningocele and the management of hydrocephalus: a national survey. Neurosurg Focus 47(4):E8, 2019

4. Sutton LN, Adzick NS, Bilaniuk LT, Johnson MP, Crombleholme TM, Flake AW: Improvement in hindbrain herniation demonstrated by serial fetal magnetic resonance imag- ing following fetal surgery for myelomeningocele. JAMA 282:1826-1831, 1999

5. Tulipan N, Bruner JP, Hernanz-Schulman M, Lowe LH, Walsh WF, Nickolaus D, et al: Effect of intrauterine myelomeningocele repair on central nervous system structure and function. Pediatr Neurosurg 31:183-188, 1999

\section{Disclosures}

The author reports no conflict of interest.

\section{Correspondence}

Erin N. Kiehna: enkiehna@novanthealth.org.

INCLUDE WHEN CITING

DOI: 10.3171/2019.8.FOCUS19641. 